\title{
Climatic fluctuations and malaria transmission dynamics, prior to elimination, in Guna Yala, República de Panamá
}

Lisbeth Amarilis Hurtado ${ }^{1 \dagger}$, José E. Calzada ${ }^{2 \dagger}$, Chystrie A. Rigg², Milagros Castillo and Luis Fernando Chaves $34^{3 *^{*}}$

\begin{abstract}
Background: Malaria has historically been entrenched in indigenous populations of the República de Panamá. This scenario occurs despite the fact that successful methods for malaria elimination were developed during the creation of the Panamá Canal. Today, most malaria cases in the República de Panamá affect the Gunas, an indigenous group, which mainly live in autonomous regions of eastern Panamá. Over recent decades several malaria outbreaks have affected the Gunas, and one hypothesis is that such outbreaks could have been exacerbated by climate change, especially by anomalous weather patterns driven by the EL Niño Southern Oscillation (ENSO).

Results: Monthly malaria cases in Guna Yala (1998-2016) were autocorrelated up to 2 months of lag, likely reflecting parasite transmission cycles between humans and mosquitoes, and cyclically for periods of 4 months that might reflect relapses of Plasmodium vivax, the dominant malaria parasite transmitted in Panamá. Moreover, malaria case number was positively associated $(P<0.05)$ with rainfall $(7$ months of lag), and negatively with the El Niño 4 index (15 months of lag) and the Normalized Difference Vegetation Index, NDVI (8 months of lag), the sign and magnitude of these associations likely related to the impacts of weather patterns and vegetation on the ecology of Anopheles albimanus, the main malaria vector in Guna Yala. Interannual cycles, of approximately 4-year periods, in monthly malaria case numbers were associated with the El Niño 4 index, a climatic index associated with weather and vegetation dynamics in Guna Yala at seasonal and interannual time scales.
\end{abstract}

Conclusion: The results showed that ENSO, rainfall and NDVI were associated with the number of malaria cases in Guna Yala during the study period. These results highlight the vulnerability of Guna populations to malaria, an infection sensitive to climate change, and call for further studies about weather impacts on malaria vector ecology, as well as the association of malaria vectors with Gunas paying attention to their socio-economic conditions of poverty and cultural differences as an ethnic minority.

Keywords: NDVI, Malaria elimination, Gunas, Plasmodium vivax, Wavelets, Seasonal autoregressive, Climate change, El Niño Southern Oscillation, Poverty, Anopheles albimanus

\footnotetext{
*Correspondence: Ifchavs@gmail.com

${ }^{\dagger}$ Lisbeth Amarilis Hurtado and José E. Calzada contributed equally to this

work

${ }^{3}$ Instituto Costarricense de Investigación y Enseñanza en Nutrición y

Salud (INCIENSA), Apartado 4-2250, Tres Ríos, Cartago, Costa Rica

Full list of author information is available at the end of the article
} 


\section{Background}

Malaria was one among many infectious vector-borne diseases that were studied and then locally eliminated as a necessary step for the building of the Panamá Canal [1, $2]$, and a disease kept under control during the development of the Canal Zone as a US colonial possession [3-5]. Pioneering research on infectious diseases in the Canal Zone showed that malaria was a major problem among indigenous populations [6, 7], a situation that, unfortunately, is currently maintained [8]. A major factor shaping this situation is the poor housing quality of the Gunas [9] and their different cultural practices [10], where a major point of pride has been keeping to a minimum the influence of Hispanic culture on Guna traditions [11]. In fact, after the independence of Panamá from Colombia a series of concessions by the Panamanian government to exploit natural resources on the ancestral lands of the Gunas, in a fashion that excluded the Gunas from their economic benefits, coupled with a series of actions that forcibly tried to incorporate the Gunas into mainstream Panamanian culture, led to a popular uprising and armed revolt in 1925: La Revolución Guna led by Nele Kantule, a major leader in the Guna struggle for self-determination and right to keep their ancestral heritage. Resolution of this conflict was negotiated through a peace treaty whereby the Panamanian government committed itself to grant special rights to the native communities of Panamá, rights finally granted with the creation of the autonomous indigenous region of Guna Yala, originally named San Blas, in 1938 [12].

The autonomy granted to the Gunas, nevertheless, has not empowered this ethnic group to improve its socio-economic and health indicators. Indeed, although Panamá is one of the countries with a high likelihood of eliminating malaria in the near future $[13,14]$, malaria is by far the most important infectious vector-borne disease affecting the Gunas, and this probably reflects the vulnerability of this ethnic group to malaria transmission as a socio-economically marginalized population [8, 15]. Today, around $90 \%$ of the malaria cases in Panamá come from the Gunas, despite being less than $3 \%$ of the total population in Panamá, and near $40 \%$ of the cases occur in the Comarca Guna Yala [16]. In this area the dominant malaria vector is Anopheles albimanus [16, 17], while the dominant parasite is Plasmodium vivax, which consistently accounts for over $90 \%$ of the cases $[18,19]$. In this scenario, where malaria transmission has been declining over recent years [8], a major concern is the role that climate change might have on malaria transmission [20,21], given the high vulnerability of the Gunas as a socially marginalized ethnic group. For example, with climate change-induced sea level rise it is expected that the core of the Guna population, who inhabit small islands in the Caribbean Sea, will need to be relocated to the mainland of Guna Yala [22], mainly to Cartí, an area with very active malaria transmission, unlike the islands where transmission is rare [16]. A previous experience of relocating Gunas inside Panamá lacked an environmental health impact assessment, and soon after Gunas from the Comarca Madugandi were relocated to the shores of Lake Bayano, several vector-borne infections affected this relocated Guna population [23]. Nowadays, the Gunas have the largest malaria burden in Panamá [8]. In that sense, it is important to understand different factors affecting malaria transmission in Guna Yala. Previous research has shown that in the nearby autonomous region of Madungandi, also inhabited by the Gunas, extreme conditions in the El Niño Southern Oscillation (ENSO) were associated with an exacerbation of malaria transmission in this region [8]. This research tests the hypothesis that ENSO and weather fluctuations might be associated with changes in malaria transmission in the Comarca Guna Yala. This research uses tools for time series analysis to assess the impact of ENSO, meteorological fluctuations (rainfall and temperature) and vegetation dynamics on malaria transmission dynamics.

\section{Methods}

Study site

The Comarca Guna Yala is located in northeastern Panamá, facing the Caribbean Sea, and bordering Colombia in the southeast (Fig. 1). The climate is classified as subequatorial with a dry season [24]. Like the rest of Panamá there is little seasonal variability in temperature which oscillates between 26 and $27^{\circ} \mathrm{C}$, with an unimodal rainfall seasonal pattern with a dry (December to April) and long rainy season (May to November). The total population of Guna Yala is around 37,000 people, with 19,500 females and 17,500 males, around $50 \%$ of the population are under 18 years of age, and around one-fifth of the population are children under 5 years old. Poverty is a major problem in the region, for example, $91.4 \%$ of the people are poor, one of the highest in Panamá according to a multidimensional poverty index developed by Panamás Ministry of Finance [25], and closely related to the fact that nearly $80 \%$ of the population is dedicated to subsistence farming and fishing [26]. More specifically, there are large differences in quality of life parameters, where the Gunas have a life expectancy of 71 years well below the average for the population of Panamá (78 years), and, in general most socio-economic indicators lag well behind those of the non-indigenous population [26].

\section{Climatic and landscape covariates}

Several weather stations are located in Comarca Guna Yala, but only two have long-term rainfall records 


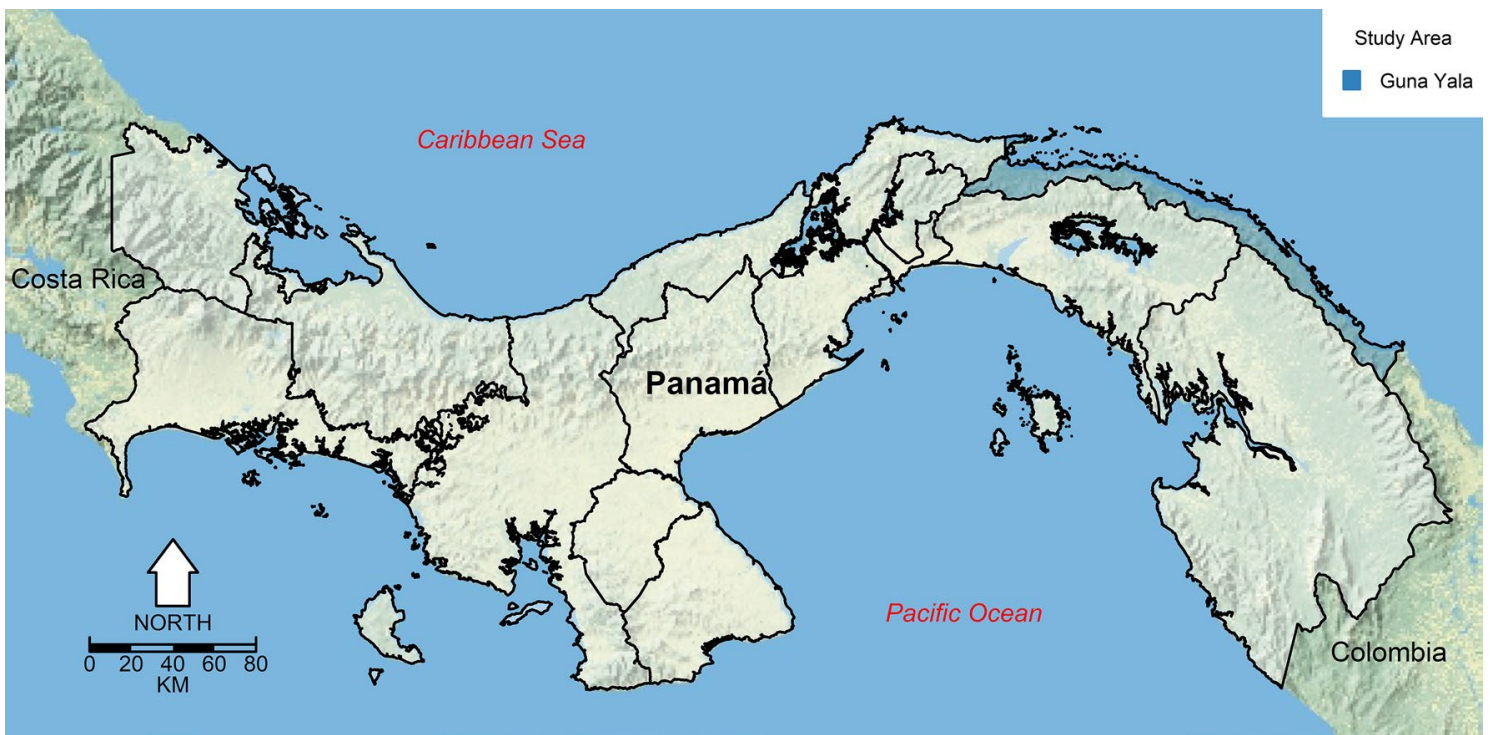

Fig. 1 Map of the República de Panamá, highlighting the location of Comarca Guna Yala. This map was made using as base a public domain map from the US National Park Service [84]

(Additional file 1: Figure S1). Therefore, to assess the impact of local weather fluctuations, data from globally interpolated gridded datasets were used. For temperature and rainfall, respectively, data from GHCN/CAMS $2 \mathrm{~m}$ and CMORPH Version 1.0 available at [27] were used. Both of these datasets are available in grids of $0.5^{\circ}$. Data were downloaded for the gridded box bounded between $8.5^{\circ} \mathrm{N}$ and $9.5^{\circ} \mathrm{N}$ and $79.25^{\circ} \mathrm{W}$ and $77.75^{\circ} \mathrm{W}$. To quantify the impacts of global climatic fluctuations the El Niño 4 time series was employed, an index for ENSO, a global climatic phenomena associated with extreme weather in Panamá [8]. Niño 4 data were downloaded from the US National Oceanic and Atmospheric Administration (NOAA) Climate Prediction Center [28]. The NOAA data were collected from the area delimited by $5^{\circ} \mathrm{N}-5^{\circ} \mathrm{S}$ and $160^{\circ} \mathrm{E}-150^{\circ} \mathrm{W}$ of the Pacific Ocean. All these time series were available from January 1998 to December 2016.

As a proxy of vegetation data, information from the MODIS land products database was extracted. Images for the Normalized Difference Vegetation Index (NDVI) from the monthly $1-\mathrm{km}$ resolution vegetation $\left(M^{*}\right.$ D13A3) product, courtesy of the NASA Land Processes Distributed Active Archive Center (LP DAAC), USGS/Earth Resources Observation and Science (EROS) Center, Sioux Falls, South Dakota [29], were employed. To download the images the package MODIStsp for the software R [30] was employed. Further GIS procedures for the downloaded images were made using the package raster also in the statistical software $R$, where each monthly image was clipped using a shapefile for Comarca Guna Yala, then stacked into a geotiff, from which the average and standard deviation for each clipped polygon was computed, thus generating a time series. MODIS NDVI based products were only available from January 2000 to December 2016.

\section{Malaria data}

Monthly malaria cases for Comarca Guna Yala, from January 1998 to December 2016, were obtained from the Departamento de Control de Vectores, Ministerio de Salud, República de Panamá. The time series records malaria cases from all over Comarca Guna Yala, although epidemic foci occurred in selected locations [16]. The time series only considers confirmed malaria cases by the examination of Giemsa-stained blood smears prepared by the thick smear method [6]. Routinely, all positive slides, and $10 \%$ of the negative slides, are confirmed by the Public Health Central Reference Laboratory of the Gorgas Laboratory [8]. This microscopic diagnostic has shown a consistent sensitivity and specificity, close to $100 \%$ in each case, confirming the quality of the data. With the exception of the 2002-2006 outbreak, where $12 \%$ of the cases were due to Plasmodium falciparum [18], over $95 \%$ of the cases are consistently due to $P$. vivax. For the subsequent time series analysis the raw number of malaria cases were analysed, provided this time series did not have trends that required the estimation of the malaria incidence rate for de-trending [31]. 


\section{Statistical analysis}

\section{Malaria cases, weather and vegetation seasonality}

Seasonality in malaria cases and the covariate time series was studied using box diagrams for each month [32].

\section{Malaria cases time series correlation structure and association with climatic variables}

For the analysis, a protocol previously applied to study malaria in Panamá was followed [8]. Briefly, the protocol starts by inspecting the autocorrelation function (ACF), i.e., the time series correlation with itself through time, and the partial autocorrelation function (PACF), i.e., the correlation between consecutive time lags [31]. With information about the significant time lags, a null autoregressive model with no covariates, was built. This null model was used to pre-whiten the time series from all covariates using the Kalman filter [31]. Pre-whitening is a process where any common autoregressive structure is removed from ancillary time series in order to study its patterns of association with a focal time series [31]. Residuals from the autonomous null model and prewhitened residuals from covariates were used to estimate cross-correlation functions (CCFs) of malaria incidence with each one of the covariates. The CCFs indicate lags at which malaria and the covariates were correlated, which were subsequently used to build models with covariates. The model that included all significant covariates was simplified by a process of backward elimination guided by the minimization of the akaike information criterion (AIC), a function that trades-off model goodness-of-fit and parameter number, and whose minimization can be used to select among models with a similar number of parameters [31]. For the best model error assumptions were verified using standard procedures for time series analysis [31].

\section{Non-stationary patterns of association in the time-frequency domain}

The association of cycles in time series over time can be studied using cross wavelet coherence analysis [33, 34]. Here, wavelet-based analysis was used to determine at a particular frequency and time in Niño 4 index and malaria, and also to see if these time series were associated with climatic covariates, i.e., temperature and rainfall, and the mean and standard deviation (SD) of NDVI in Comarca Guna Yala.

\section{Results}

During the study period (1998-2016) there was a total of 3082 malaria cases in Guna Yala, with a monthly average $( \pm \mathrm{SD})$ of $13.52 \pm 14.03$. Seasonal patterns in the studied time series are presented in Fig. 2. For malaria cases (Fig. 2a), there was no clear seasonality, with the number of cases being low, around 10 cases per month, throughout the year. In all months but January there were epidemics of 30 or more cases (Fig. 2a). The median Niño 4 index (Fig. 2b) tended to be lower during the first 4 months of the year, January to April, but there was relatively little seasonal variability in this index. Meanwhile, rainfall (Fig. 2c) had a clearly marked seasonality, where December to April are dry, and the rest of the year is rainy, reaching a peak in July. Temperature (Fig. 2d) has its seasonality contrasting with rainfall, where the dryer months are the hottest months, temperatures reaching a monotonic peak in April. The NDVI showed a bimodal pattern (Fig. 2e) reaching a first peak in May and then in September, with an absolute minimum in December. By contrast, seasonality in the NDVI SD reached peaks when the NDVI is lowest, e.g., in January and December (Fig. 2f).

Figure 3 shows the studied monthly time series highlighting ENSO phases. At the beginning of the study period (2000-2004), two malaria epidemics occurred during the cold and hot phases of ENSO, and overall it seems from the plot that malaria cases increased with ENSO, especially during the hot phase (Fig. 3a). During these periods the Niño 4 index (Fig. 3b) has its maximum and minimum, while rainfall tends to decrease during the hot phase of ENSO (Fig. 3c) a time when temperature increases in Guna Yala (Fig. 3d). For NDVI there is no clear increase or decrease, both on its mean value (Fig. 3e) or SD (Fig. 3f) that could be associated with specific ENSO phases.

Autocorrelation patterns in the malaria time series, and its association with the different covariates are presented in Fig. 4, considering data between January 2000 and December 2016. Only for this period there was information about all covariates, while there was data for Niño 4, rain and temperature for 1998-2016, and for comparison, results for this time period are presented in Additional file 2: Figure S2. Figure 4a shows that malaria had a descending autoregressive pattern, suggestive of a significant degree of autocorrelation in the time series. A similar pattern is also observed for the time series between 1998 and 2016 (Additional file 2: Figure S2A). More specifically, the time series had a significant partial autocorrelation (Fig. 4b) at times lags 1, 2 and 4 months, which were also significant when considering data from 1998 and 1999 (Additional file 2: Figure S2B). Malaria cases were negatively associated at a time lag of 15 months (Fig. 4c, Additional file 2: Figure S2C), and positively with rain at 7 months of lag (Fig. 4d, with no significance when considering data for 1998-2016, see Additional file 2: Figure S2D), and no significant association was observed with temperature independently of the studied time frame (Fig. 4e, Additional file 2: Figure 

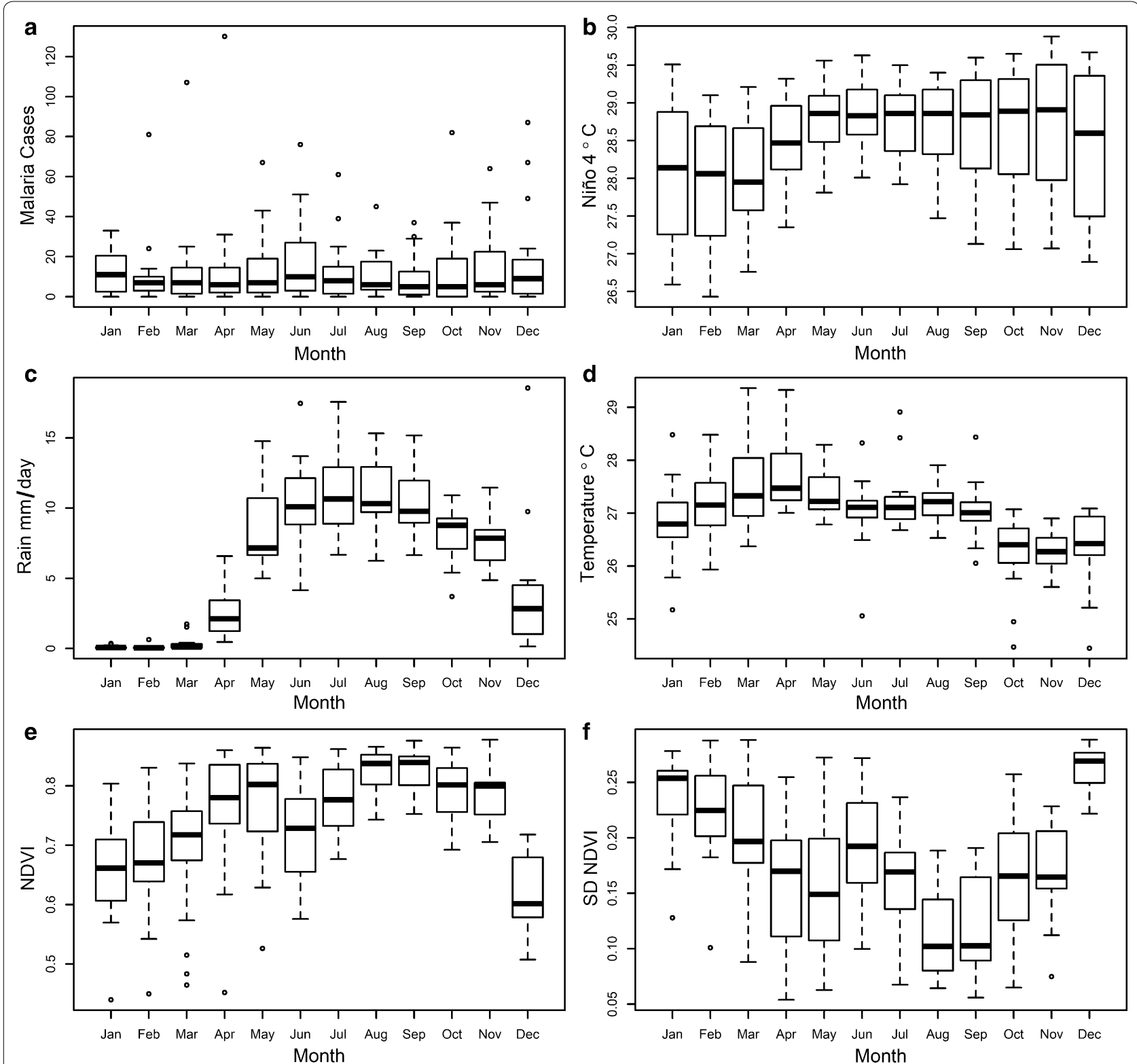

Fig. 2 Seasonal patterns. a Malaria (b) Niño 4 (c) rainfall (d) temperature (e) average NDVI (f) SD NDVI. In the boxplots, middle bars indicate median values

S2E). Malaria was negatively associated with NDVI at 8 months of lag (Fig. 4f) and no association was observed with the SD of NDVI (Additional file 3: Figure S3). The information from the correlation patterns was used to build seasonal autoregressive models (Table 1), which considered 2 monthly time lags as autoregressive, and a seasonal autoregressive component with 4 months of lag (Fig. 4b). One model did not include any covariate, while another included the 3 covariates that were identified as significantly associated with the number of malaria cases, i.e., the El Niño 4 index with 15 months of lag (Fig. 4c), rainfall with 7 months of lag (Fig. 4d) and NDVI with 8 months of lag (Fig. 4f). This model with all covariates had the minimum AIC when compared with the model without covariates, and simpler models (Table 1).

Parameter estimates for the best model are presented in Table 2. All coefficients were statistically significant $(\mathrm{P}<0.05)$. Meanwhile, as observed in the CCFs, the association of monthly malaria case number was negative with the El Niño 4 index (Fig. 4c), NDVI (Fig. 4f) and positive with rainfall (Fig. 4d), the relationship of monthly malaria case number being largest with NDVI (Table 2). 

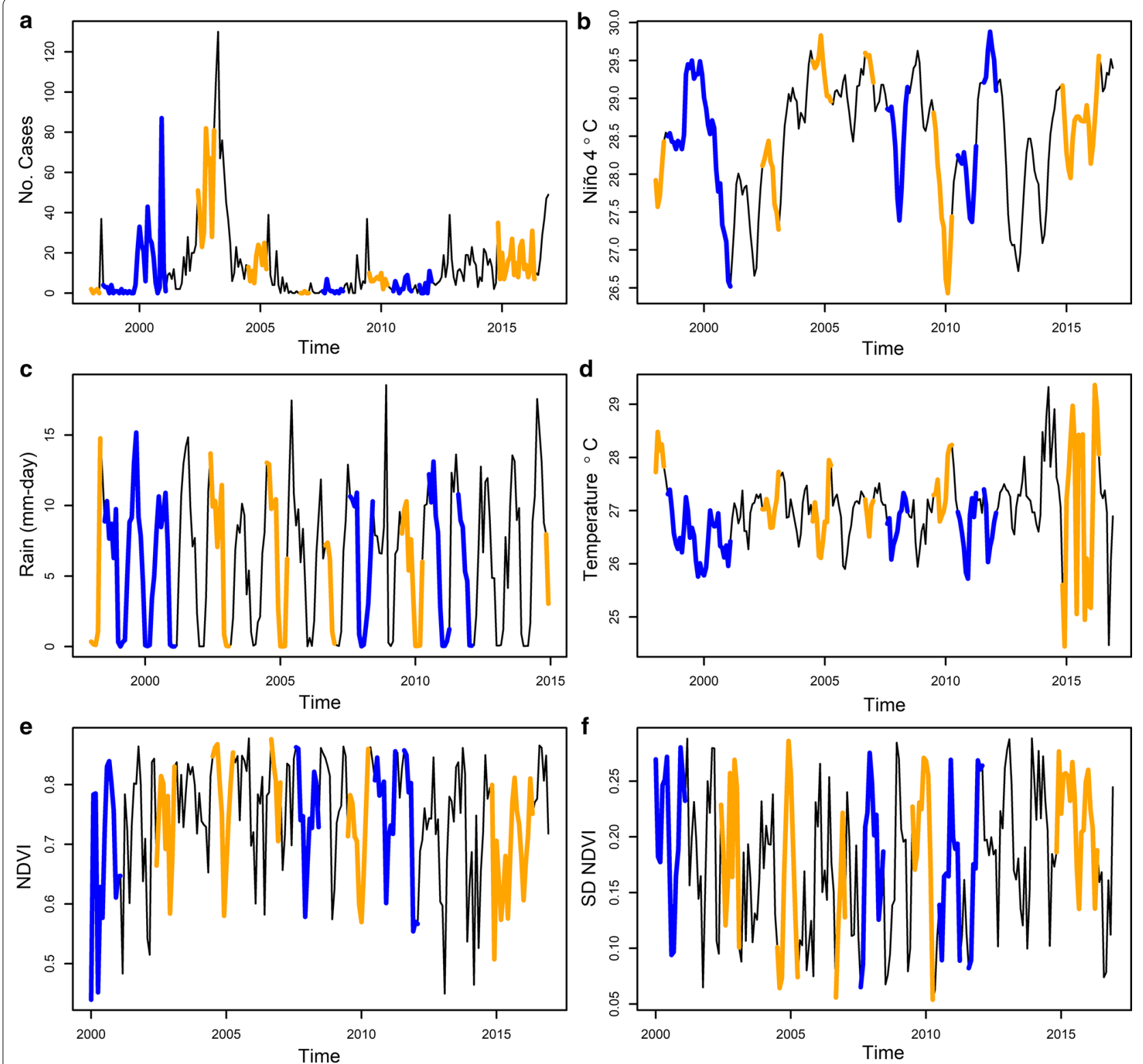

Fig. 3 Monthly time series. a Malaria (b) Niño 4 (c) rainfall (d) temperature (e) average NDVI (f) SD NDVI. In all panels, blue indicates the cold phase of the El Niño southern oscillation, while orange the hot phase

As suggested by the changing significance of the association between malaria cases and, for example, rainfall (Fig. 4d and Additional file 2: Figure S2), the association between malaria case number and the covariates were considered highly non-stationary, changing on time and frequency (Fig. 5). This result is confirmed when looking at the wavelet cross-coherence between the monthly number of malaria cases and the El Niño 4 index (Fig. 5a), which suggests interannual cycles, of 4-year periods or more, between the two time series are associated. The association of malaria with the other time series was more localized, and prominent at seasonal time scales (1-year period) or biennial, as was the case with rainfall (Fig. 5b), and to a lesser extent with temperature (Fig. 5c), NDVI (Fig. 5d) and the SD of NDVI (Fig. 5e). Meanwhile, the cross wavelet coherence analyses suggest that impacts of El Niño 4 impacts of the climatic and vegetation covariates at Guna Yala were widely significant $(\mathrm{P}<0.05)$ during the study period. For rainfall, associations were stronger at the seasonal and biennial time scales (Fig. 5f), while for temperature a similar pattern was observed, but also 


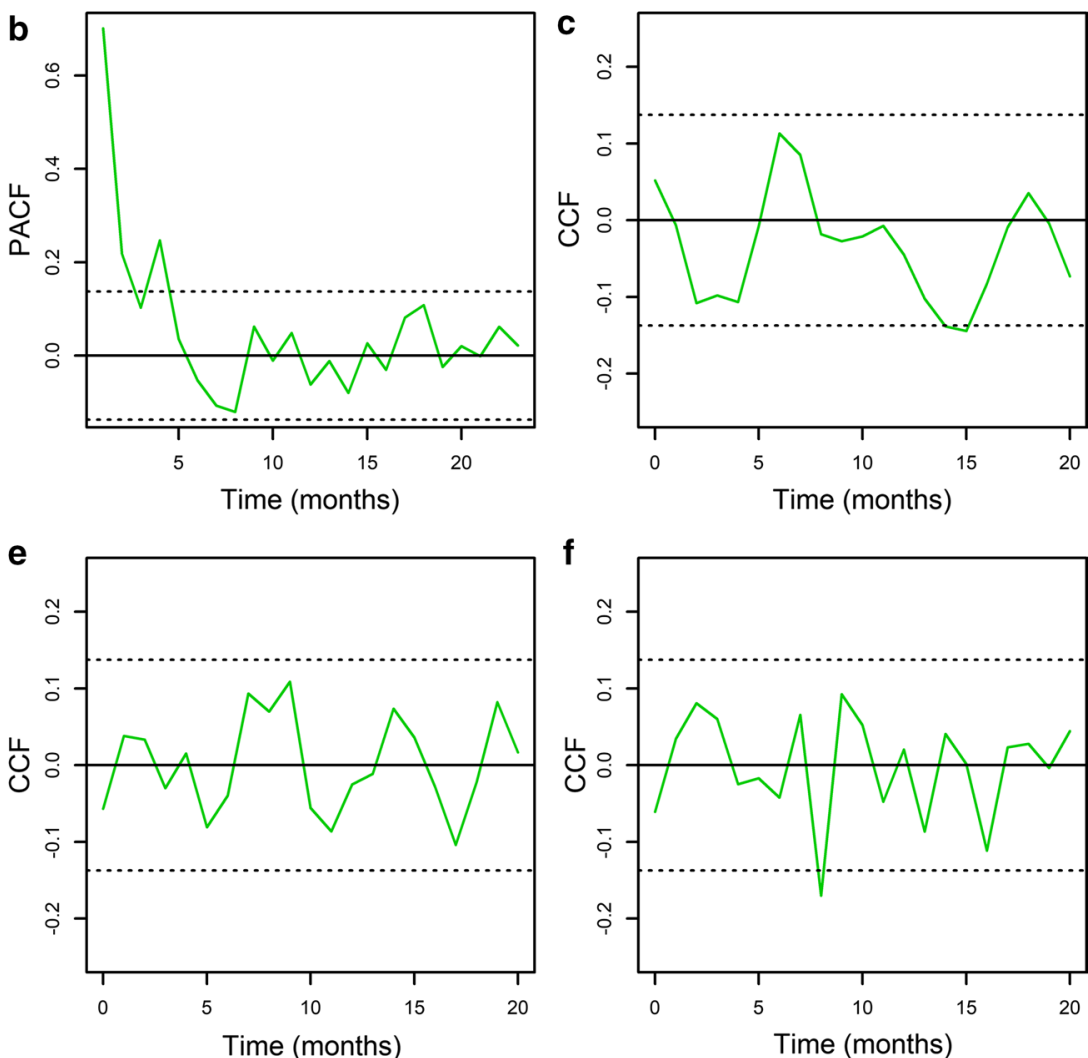

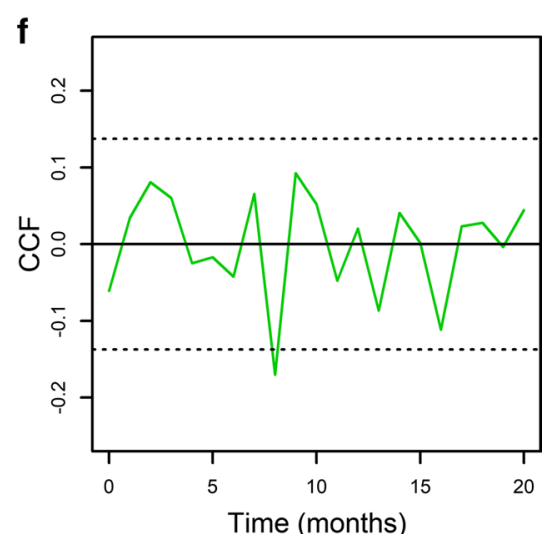

Fig. 4 Correlation functions for the 2000-2016 monthly time series. a Malaria time series autocorrelation function (ACF). b Malaria time series partial autocorrelation function (PACF). Cross correlation function (CCF) between malaria and $\mathbf{c}$ Niño 4 (d) rainfall (e) temperature (f) average NDVI. In the plot panels, orange lines indicate the value of the correlation function, the black solid line indicates a correlation value of 0 , while the dotted lines indicate $95 \%$ confidence intervals within which correlations are expected by chance. Time lags in the $x$ axis of all panels are in months

\section{Table 1 Time series model selection}

\begin{tabular}{ll}
\hline Parameters (lag) & AIC \\
\hline Intercept, AR(1), AR(2), SAR(4) & 1571.27 \\
Intercept, AR(1), AR(2), SAR(4), Niño 4(15), rain(7), NDVI(8) & 1559.89 \\
Intercept, AR(1), AR(2), SAR(4), Niño 4(15), rain(7), & 1568.70 \\
Intercept, AR(1), AR(2), SAR(4), Niño 4(15), NDVI(8) & 1562.46 \\
Intercept, AR(1), AR(2), SAR(4), rain(7), NDVI(8) & 1562.75 \\
Intercept, AR(1), AR(2), SAR(4), Niño 4(15) & 1568.41 \\
Intercept, AR(1), AR(2), SAR(4), rain(7) & 1569.72 \\
Intercept, AR(1), AR(2), SAR(4), NDVI(8) & 1568.04 \\
\hline
\end{tabular}

Parameters indicate the parameters considered in each model

AIC Akaike information criterion is minimized for the best model, indicated in italic type. Parameters include: $A R$ autoregressive, SAR seasonal AR, Niño 4, rain and NDVI, lags are in months

with a significant coherence at interannual time scales of 4 years or more (Fig. 5g). Finally, NDVI (Fig. 5h) and SD of NDVI (Fig. 5i) were associated seasonally and interannually, for cycles of 4-year periods, with the El Niño 4 index.

\section{Discussion}

Mesoamerica, the geographic region traversing southern México to Panamá, is a region where around 3\% of malaria cases occur in the New World [35]. Most countries in Mesoamerica achieved the World Health Assembly (WHA) target for the Millennium development goals (MDG) of reducing by $75 \%$ malaria cases when compared with 2000 $[35,36]$. Nevertheless, Panamá, despite having the highest economic growth in Mesoamerica [37], was the only country unable to achieve the MDG for malaria reduction. In fact, the 874 malaria cases reported in 2014 represented only a $15.6 \%$ decrease in annual malaria cases when compared with 2000 [36]. Most malaria cases, over $85 \%$ of the total, occur in indigenous groups that inhabit the autonomous regions of the country, which are socially marginalized and vulnerable populations, and where the use of conventional tools for malaria control is less effective than among other groups [8]. This failure might reflect the alarming social and health inequalities affecting the Gunas [26], but also a lack of intercultural understanding [10]; other factors, including geographical isolation, internal movement of Gunas across the region and cross-border 
Table 2 Parameter estimates for the best time series model explaining the number of malaria cases in Comarca Guna Yala (2000-2016), Panamá

\begin{tabular}{lclr}
\hline Parameter (Lag) & Estimate & SE & Z \\
\hline Intercept & 37.896 & 7.854 & $4.825^{*}$ \\
AR(1) & 0.532 & 0.072 & $7.389^{*}$ \\
AR(2) & 0.16 & 0.074 & $2.162^{*}$ \\
SAR(4) & 0.263 & 0.088 & $2.989^{*}$ \\
Niño 4(15) & -5.61 & 2.503 & $-2.241^{*}$ \\
Rain(7) & 0.508 & 0.237 & $2.143^{*}$ \\
NDVI(8) & -30.946 & 9.367 & $-3.304^{*}$ \\
Error variance & 153.5 & & \\
\hline
\end{tabular}

Parameters include: $A R$ autoregressive, SAR seasonal AR, Niño 4, rain and NDVI, lags are in months

* Statistically significant, $\mathrm{P}<0.05$

movement of people between Colombia and Guna Yala, have further constrained the success of efforts to control malaria in this region, thus favouring malaria transmission in an epidemic-prone fashion $[16,19]$.

Moreover, Guna Yala is highly vulnerable to climate change, mainly because of its geography characterized by an extended coastline on the Caribbean Sea with many inhabited small islands [38]. In fact, global warmingassociated rise in sea level and subsequent reduction in surface area of some islands has already caused the displacement of some Guna populations to mainland areas $[22,39]$, where there is a higher risk for malaria transmission [16]. Nevertheless, climate change also affects malaria transmission by impacting the population dynamics of vectors [40] and the relationship of vectors and parasites [41, 42], whose understanding can help to optimize the targeting of control strategies by the Panamanian National Malaria Control Programme. In this sense, this study explored the impact of ENSO, meteorological fluctuations (rainfall and temperature) and vegetation on malaria transmission dynamics in Guna Yala.

During the study period (1998-2016), the monthly number of malaria cases was relatively low and homogenously distributed throughout the years. Epidemics were observed in all months, except for January, a behaviour that can be exploited to intensify control activities or implement intervention measures such as mass drug administration during that month, as done elsewhere [43]. The monthly malaria cases autocorrelation observed at 1 and 2 months lag likely reflect parasite transmission cycles between humans and Anopheles spp. mosquitoes $[44,45]$. Similarly, the 4 months lag is likely related to relapses of $P$. vivax [46-49], which have been described as occurring between 3 and 7 months with an average of 5 months in P. vivax strains from Panamá [50], the dominant malaria parasite transmitted in Panamá, including Guna Yala [16].

National drug policy on malaria in Panamá recommends chloroquine in combination with primaquine as first-line treatment for P. vivax infections [18]. The World Health Organization recommends a 14-day course of primaquine to eradicate the liver stage of the parasite and prevent relapse of the disease [18]. However, in most of Panamá, particularly in hard-to-reach areas as Guna Yala, primaquine is administered for only 7 days [51]. Shorter regimens compared to the standard 14-day primaquine have been associated with higher



Fig. 5 Cross wavelet coherence analysis for monthly time series. Panels show the cross-wavelet coherence between: a malaria and the El Niño 4 index, $\mathrm{NI}(\mathbf{b})$ malaria and rainfall (c) malaria and temperature (d) malaria and NDVI (e) malaria and SD of NDVI (f) NI and rainfall (g) NI and temperature (h) NI and NDVI (i) NI and SD of NDVI. A coherence scale is presented on the right-hand side of the figure, which goes from zero (blue) to one (red). Red regions in the plots indicate frequencies and times for which the two series share power (i.e., variability). The cone of influence (within which results are not influenced by the edges of the data) and the significant coherent time-frequency regions $(P<0.05)$ are indicated by black solid lines. Note that cross-wavelet analysis including NDVI data are for 2000-2016, while all other analyses are for $1998-2016$ 
relapse rates [52]. Moreover, due to their traditional beliefs and practices, Gunas do not adhere well to treatments they consider foreign to their culture [10]. Thus, many Guna patients fail to complete the full dosage, resulting in inadequate blood drug concentration that favours relapse [51].

Environmental covariates with significant associations $(\mathrm{P}<0.05)$ were rainfall, positively associated with 7 months of lag, and cases were negatively associated with the El Niño 4 index (15 months of lag) and the NDVI (8 months of lag). These relatively long delays might emerge as consequence amplifying cycles of transmission, a phenomenon previously described in East Africa [53], where a triggering environmental disturbance has an effect that exacerbates through time via the amplification of those environmental signals, for example, by mosquito vectors [40]. These long lags might also reflect an association with a harmonic of a cycle from a shorter period [54]. In plain words, if there is a cycle of 2 months associated with the life cycle of the parasite, then the incidence can also be expected to be associated at 4, 6 and 8 months, which are harmonics of 2 months. Then if rainfall itself has an autocorrelated pattern, where 7 months is a natural cycle, one can expect the association to be stronger due to a phenomenon known in physics as 'resonance' $[54,55]$ that emerges in coupled oscillators (which metaphorically can be used to describe vector-borne disease, mosquito and rainfall association [56]) and which increases the association at time lags that correspond to rainfall cycles or rainfall impact on malaria transmission. Moreover, here it is important to highlight the extensively validated methods employed for this analysis [31], warrant that these lags are not spurious results. The ENSO is considered a potential driver of malaria transmission in endemic regions across the globe $[44,53$, 57-64], and for other tropical diseases in the region [34, 65-67]. Panamá, with extended coastlines in the Pacific and the Caribbean, is highly vulnerable to the impact of this global climatic phenomenon [68]. In fact, ENSO events may trigger heavy rainfall in the Caribbean coast and at the same time severe and prolonged drought in the Pacific Coast $[68,69]$. In this sense, this study also found that interannual cycles, of approximately 4 -year periods, in monthly malaria case numbers were significantly associated with ENSO, measured by El Niño 4 index. This result is similar to that previously found in the Madungandi autonomous region, a nearby mainland region also inhabited by the Gunas [8].

About the other environmental covariates associated with malaria cases in Guna Yala, it is well known that rainfall is necessary to form water pools that are used by Anopheles spp. as breeding and larval sites [2, 20, 21]. This is important in Guna Yala as many of the inhabited islands lack fresh water and many temporal water pools suitable for Anopheles spp. breeding are formed soon after the rainy season ends [16]. Although temperature has a critical impact on mosquito and parasite traits that determine the transmission potential of malaria [41, 42, 70], this analysis did not find a significant association with malaria cases in Guna Yala. This is probably related to the lack of a marked seasonality that could disrupt Plasmodium spp. development in Anopheles spp. mosquitoes, with the average temperature of $26.99^{\circ} \mathrm{C}$ (range $24.45-29.36{ }^{\circ} \mathrm{C}$ ] close to $26.00{ }^{\circ} \mathrm{C}$ (range $17.00-33.00{ }^{\circ} \mathrm{C}$ ) a temperature deemed optimal for malaria transmission [42]. Meanwhile, the negative impact of NDVI might be related with local ecological conditions [58, 71], where the excessive increase of vegetation biomass is detrimental for population dynamics of An. albimanus and other dominant vector species present in Guna Yala, mainly Anopheles aquasalis and Anopheles punctimacula [72-74]. Indeed, it is very important to highlight the importance of local ecological conditions for different dominant malaria vector species. For example, An. albimanus which is considered the main malaria vector in Guna Yala [16], breeds in a wide variety of aquatic habitats with several types of aquatic vegetation [2,74], but with a biology sensitive to shade [2] which might explain the negative impact of increased terrestrial vegetation. By contrast, An. punctimacula shows preference for shallow waters shaded by coconut palms [16, 17], while An. aquasalis breeding sites are mainly mangroves and coastal wetlands, and its abundance has been associated with salinity [75, 76]; ecological characteristics predominant in most Guna settlements in Guna Yala. Interestingly, this latter vector species has a restricted distribution in Panamá, but is particularly prevalent in Guna Yala, being the primary vector in some communities of this region [17]. Probably these other vectors, better suited to local habitats observed in Guna Yala, may be responsible for malaria transmission, but that is open to further research.

Finally, some limitations of this study need to be highlighted: for the analysis $P$. vivax and $P$. falciparum data were together as total malaria cases because, with the exception of the 2004 epidemic [18], over $95 \%$ of the cases were due to $P$. vivax during the study period. Besides this, there might be some problems in the accuracy of case detection given the passive nature of the malaria surveillance system, a problem common in other malariaendemic regions [46, 77]. Similarly, the lack of association with temperature might be an artifact of the geographical scale of the study, given that at small geographical scales temperature is important for mosquito biology and the parasite vector interaction $[41,75]$. There is the pervasive problem of ignoring other contextual drivers of malaria transmission such as poverty $[8,78,79]$, parasite invasion 
through unplanned migration $[19,80]$, and the understudied socio-cultural barriers to accept and implement malaria control measures among the Gunas [10].

\section{Conclusions}

Results from this study showed that ENSO, rainfall and NDVI were associated with the number of malaria cases in Guna Yala during the study period (1998-2016). These results highlight the vulnerability of Guna population to malaria, an infection sensitive to climate change, and call for further studies about weather impact on malaria vector ecology, especially the temporal impact of weather fluctuations on population dynamics [81, 82], something that has not been done for An. albimanus in the Comarca Guna Yala of Panamá, as well as the association of malaria vectors with the Gunas, paying special attention to their socio-economic conditions of poverty and cultural differences as an ethnic minority. Other biological factors, such as the influx of malaria parasites by the migration of the Gunas across their ancestral territory, and other ethnic migrant groups: all of these conditions favour malaria transmission in the landscape inhabited by the Gunas. Information on the potential impact of climate factors on malaria incidence might be helpful to guide malaria prevention programmes aimed at the eventual elimination of this disease, from República de Panamá and Mesoamerica. For example, strategic interventions in the vulnerable region of Guna Yala, should include comprehensive health impact assessments [21, $79,83]$ with a focus in areas foreseen to see large influx of climate change triggered Guna migration, such as Carti, a site already chosen for island Guna population relocation following the disappearance of the Caribbean Islands currently serving as home for most of the Gunas living in Guna Yala.

\section{Additional files}

Additional file 1: Figure S1. Rainfall time series. (A) Mulatupo $(9.000259$, - 77.866676) and (B) Nargana (9.444246, - 78.585331). Data are courtesy of ETESA, Panamanian National Electrical Company.

Additional file 2: Figure S2. Correlation functions for the 1998-2016 monthly time series. (A) Malaria time series autocorrelation function (ACF) (B) Malaria time series partial autocorrelation function (PACF). Cross correlation function (CCF) between malaria and (C) Niño 4 (D) rainfall (E) temperature. In the plot panels, orange lines indicate the value of the correlation function, the black solid line indicates a correlation value of 0 , while the dotted lines indicate $95 \%$ confidence intervals within which correlations are expected by chance. Time lags in the $\mathrm{x}$ axis of all panels are in months.

Additional file 3: Figure S3. Cross correlation function between malaria and SD NDVI. The orange line indicates correlation function values at different time lags (in months), the black solid line indicates a correlation value of 0 , while the dotted lines indicate $95 \%$ confidence intervals within which correlations are expected by chance.

\section{Abbreviations}

ENSO: El Niño Southern Oscillation; NOAA: National Oceanic and Atmospheric Administration; NDVI: normalized difference vegetation index; LP DAAC : NASA Land Processes Distributed Active Archive Center; EROS: USGS/Earth Resources Observation and Science; ACF: autocorrelation function; PACF: partial autocorrelation function; CCF: cross-correlation function; AIC: Akaike information criterion; AR: autoregressive; SAR: seasonal autoregressive; SD: standard deviation; WHA: World Health Assembly; MDG: Millennium development goals.

\section{Authors' contributions}

LH, CAR, JEC, and LFC designed the study. LH, MC and LFC managed the data and performed the analysis. LH, JEC and LFC interpreted data and results, and drafted the manuscript. All authors read and approved the final manuscript.

\section{Author details}

${ }^{1}$ Unidad de Análisis Epidemiológico y Bioestadísticas, Instituto Commemorativo Gorgas de Estudios de la Salud, Panamá, República de Panamá. ${ }^{2}$ Departamento de Investigación en Parasitología, Instituto Commemorativo Gorgas de Estudios de la Salud, Panamá, República de Panamá. ${ }^{3}$ Instituto Costarricense de Investigación y Enseñanza en Nutrición y Salud (INCIENSA), Apartado 4-2250, Tres Ríos, Cartago, Costa Rica. ${ }^{4}$ Programa de Investigación en Enfermedades Tropicales (PIET), Escuela de Medicina Veterinaria, Universidad Nacional, Apartado Postal 304-3000 Heredia, Costa Rica.

\section{Acknowledgements}

We thank Lorenzo Caceres and Zahir Dutari for their input during research development. We also thank the Vector Control Department of the Ministry of Health for providing malaria case data.

\section{Competing interests}

The authors declare that they have no competing interests. JEC is a member of the Sistema Nacional de Investigación (SNI), SENACYT, República de Panamá.

\section{Availability of data and materials}

All data used in this article are publicly available in the sources indicated in the previous sections.

\section{Consent for publication}

All authors agreed to the publication of this article.

\section{Ethics approval and consent to participate}

The publication of this study was approved by the Instituto Commemorativo Gorgas de Estudios de la Salud. No individual data were employed.

\section{Funding}

This investigation received administrative and financial support from the Gorgas Institute, the Ministry of Health and the Ministry of Economy (Grant: 9044-024) from the República de Panamá. The funders had no role on the decision to publish.

\section{Publisher's Note}

Springer Nature remains neutral with regard to jurisdictional claims in published maps and institutional affiliations.

Received: 22 November 2017 Accepted: 13 February 2018

Published online: 20 February 2018

References

1. Gorgas WC. The conquest of the tropics for the white race. JAMA. 1909;52:1967-9.

2. Zetek J. Behavior of Anopheles albimanus Wiede and tarsimaculata Goeldi. Ann Entomol Soc Am. 1915;8:221-71.

3. Gorgas WC. Anti-mosquito work at Panama. Proc R Soc Med. 1914;31:32-40. 
4. Sutter PS. Nature's agents or agents of empire? Entomological workers and environmental change during the construction of the Panama Canal. Isis. 2007;98:724-54

5. Dehné EJ. Fifty years of malaria control in the Panama area. Am J Trop Med Hyg. 1955:4:800-11.

6. Kendall Al. Malarial infection in certain native villages of the canal zone. JAMA. 1906;46:1266-73

7. Kendall Al. Malarial infection in certain native villages of the canal zone. JAMA. 1906:46:1151-4.

8. Hurtado LA, Cáceres L, Chaves LF, Calzada JE. When climate change cou ples social neglect: malaria dynamics in Panamá. Emerg Microbes Infect. 2014;3:e27.

9. Obaldia N. Determinants of low socio-economic status and risk of Plasmodium vivax malaria infection in Panama (2009-2012): a case-control study. Malar J. 2015;14:14

10. Cáceres L, Calzada JE, Gabster A, Young J, Márquez R, Torres R, et al. Social representations of malaria in the Guna indigenous population of Comarca Guna de Madungandi, Panama. Malar J. 2017;16:256.

11. Apgar MJ, Allen W, Moore K, Ataria J. Understanding adaptation and transformation through indigenous practice: the case of the Guna of Panama. Ecology Society. 2015;20:45.

12. Valiente López A. La jurisdicción indígena en la legislación Panameña. In: Huber R, Martinez JC, Lachenal C, Ariza R, Eds. Hacia sistemas juridicos plurales. México: Konrad Adenauer Stiftung; 2008:203-37.

13. Cohen JM, Moonen B, Snow RW, Smith DL. How absolute is zero? An evaluation of historical and current definitions of malaria elimination. Malar J. 2010:9:213.

14. Herrera S, Quiñones ML, Quintero JP, Corredor V, Fuller DO, Mateus JC, et al. Prospects for malaria elimination in non-Amazonian regions of Latin America. Acta Trop. 2012;121:315-23.

15. Cohen JM, Smith DL, Cotter C, Ward A, Yamey G, Sabot OJ, et al. Malaria resurgence: a systematic review and assessment of its causes. Malar J. 2012:11:122.

16. Calzada JE, Marquez R, Rigg C, Victoria C, De La Cruz M, Chaves LF, et al. Characterization of a recent malaria outbreak in the autonomous indigenous region of Guna Yala, Panama. Malar J. 2015;14:459.

17. Loaiza JR, Bermingham E, Scott ME, Rovira JR, Conn JE. Species composition and distribution of adult Anopheles (Diptera: Culicidae) in Panama. Med Entomol. 2008;45:841-51

18. Calzada JE, Samudio F, Bayard V, Obaldia N, de Mosca IB, Pascale JM. Revising antimalarial drug policy in Central America: experience in Panama. Trans R Soc Trop Med Hyg. 2008;102:694-8.

19. Obaldia N, Baro NK, Calzada JE, Santamaria AM, Daniels R, Wong W, et al. Clonal Outbreak of Plasmodium falciparum Infection in Eastern Panama. J Infect Dis. 2015;211:1087-96.

20. Chaves LF, Koenraadt CJM. Climate change and highland malaria: fresh air for a hot debate. Q Rev Biol. 2010;85:27-55.

21. Lindsay SW, Birley $\mathrm{MH}$. Climate change and malaria transmission. Ann Trop Med Parasitol. 1996:90:573-88.

22. Displacement Solutions. Cambio climático y desplazamiento en la región autónoma de Guna Yala. Panamá: Displacement Solutions; 2014.

23. Galindo P, Adames A, Peralta P, Johnson C, Read R. Impacto de la hidroeléctrica de Bayano en la transmisión de arbovirus. Rev Méd Panamá. 1983;8:89-134.

24. Autoridad Nacional del Ambiente. Atlas Ambiental de la República de Panamá. Ciudad de Panamá: Editora Novo Art; 2010.

25. Ministerio de Economia y Finanzas. Indice de Pobreza Multidimensional de Panamá Año 2017:2017.

26. Programa de las Naciones Unidas Para el Desarrollo. Atlas de Desarrollo Humano Local: Panamá 2015:2015.

27. KMNI Climate Explorer [http://climexp.knmi.nl].

28. NOAA Climate Prediction Center [http://www.cpc.ncep.noaa.gov/data/ indices/ersst3b.nino.mth.81-10.ascii].

29. NASA Land Processes Distributed Active Archive Center [https://lpdaa c.usgs.gov]

30. Busetto L, Ranghetti L. MODIStsp: an R package for automatic preprocessing of MODIS Land Products time series. Comp Geosci. 2016;97:40-8.

31. Shumway RH, Stoffer DS. Time series analysis and its applications. 3rd ed New York: Springer; 2011.

32. Venables WN, Ripley BD. Modern applied statistics with S. New York: Springer; 2002.
33. Cazelles B, Chavez M, Magny GC, Guégan J-F, Hales S. Time-dependent spectral analysis of epidemiological time-series with wavelets. J R Soc Interface. 2007:4:625-36.

34. Chaves LF, Calzada JE, Valderama A, Saldaña A. Cutaneous leishmaniasis and sandfly fluctuations are associated with El Niño in Panamá. PLoS Negl Trop Dis. 2014;8:e3210.

35. PAHO. Report on the Situation of Malaria in the Americas, 2000-2015 Document prepared by the Regional Malaria Program, Pan American Health Organization with data from Annual Country Reports. Washington D.C.: Pan American Health Organization; 2016.

36. Organization PAHO. Report on the situation of Malaria in the Americas, 2014. Washington D.C.: Pan American Health Organization; 2016.

37. Panama Country Report [http://country.eiu.com/panama].

38. Martínez Mauri M. La autonomía indígena en Panamá: la experiencia del pueblo kuna (siglos XVI-XXI). Quito: Senacyt Panamá Editorial Abya Yala; 2011

39. Guzmán HM, Guevara C, Castillo A. Natural disturbances and mining of Panamanian coral reefs by indigenous people. Conserv Biol. 2003; 17:1396-401

40. Pascual M, Ahumada JA, Chaves LF, Rodo X, Bouma M. Malaria resurgence in the East African highlands: temperature trends revisited. Proc Natl Acad Sci USA. 2006;103:5829-34.

41. Chaves LF. Climate change and the biology of insect vectors of human pathogens. In: Johnson S, Jones H, editors. Invertebrates and Global Climate Change. Chichester: Wiley; 2017. p. 126-47.

42. Shapiro LL, Whitehead SA, Thomas MB. Quantifying the effects of temperature on mosquito and parasite traits that determine the transmission potential of human malaria. PLoS Biol. 2017;15:e2003489.

43. Kaneko A, Taleo G, Kalkoa M, Yamar S, Kobayakawa T, Björkman A Malaria eradication on islands. Lancet. 2000;356:1560-4.

44. Chaves LF, Kaneko A, Taleo G, Pascual M, Wilson ML. Malaria transmission pattern resilience to climatic variability is mediated by insecticidetreated nets. Malar J. 2008;7:100.

45. Garnham PCC. Malaria parasites and other haemosporidia. Oxford: Blackwell Scientific Publications Ltd.; 1966.

46. Chaves LF, Kaneko A, Pascual M. Random, top-down, or bottom-up coexistence of parasites: malaria population dynamics in multi-parasitic settings. Ecology. 2009:90:2414-25.

47. Boyd MF, Kitchen SF. Vernal vivax activity in persons simultaneously inoculated with Plasmodium vivax and Plasmodium falciparum. Am J Trop Med Hyg. 1938;18:505-14.

48. Boyd MF, Kitchen SF. Renewed clinical activity in naturally induced vivax malaria. Am J Trop Med Hyg. 1944;24(Suppl 1):221-34.

49. Olliaro PL, Barnwell JW, Barry A, Mendis K, Mueller I, Reeder JC, et al. Implications of Plasmodium vivax biology for control, elimination, and research. Am J Trop Med Hyg. 2016;95:4-14.

50. Contacos PG, Collins WE, Jeffery GM, Krotoski WA, Howard WA. Studies on the characterization of Plasmodium vivax strains from Central America. Am J Trop Med Hyg. 1972;21:707-12.

51. Samudio F, Santamaría AM, Obaldía NI, Pascale JM, Bayard V, Calzada JE. Prevalence of Plasmodium falciparum mutations associated with antimalarial drug resistance during an epidemic in Kuna Yala, Panama, Central America. Am J Trop Med Hyg. 2005;73:839-41.

52. Rishikesh K, Saravu K. Primaquine treatment and relapse in Plasmodium vivax malaria. Pathog Glob Health. 2016:110:1-8.

53. Pascual M, Cazelles B, Bouma MJ, Chaves LF, Koelle K. Shifting patterns: malaria dynamics and rainfall variability in an African highland. Proc Biol Sci. 2008:275:123-32.

54. Chaves LF, Scott TW, Morrison AC, Takada T. Hot temperatures can force delayed mosquito outbreaks via sequential changes in Aedes aegypti demographic parameters in autocorrelated environments. Acta Trop. 2014:129:15-24.

55. Nisbet RM, Gurney WSC. Population dynamics in a periodically varying environment. J Theor Biol. 1976:56:459-75.

56. Shaman J, Day JF. Reproductive phase locking of mosquito populations in response to rainfall frequency. PLOS ONE. 2007:2:e331.

57. Chaves LF, Hashizume M, Satake A, Minakawa N. Regime shifts and heterogeneous trends in malaria time series from Western Kenya Highlands. Parasitology. 2012;139:14-25. 
58. Bouma MJ, Siraj A, Rodo X, Pascual M. El Niño-based malaria epidemic warning for Oromia, Ethiopia, from August 2016 to July 2017. Trop Med Int Health. 2016;21:1481-8.

59. Bouma MJ, Poveda G, Rojas W, Chavasse D, Quiñones M, Cox J, Patz J. Predicting high-risk years for malaria in Colombia using parameters of $E$ Niño Southern Oscillation. Trop Med Int Health. 1997;2:1122-7.

60. Laguna F, Grillet ME, León JR, Ludeña C. Modelling malaria incidence by an autoregressive distributed lag model with spatial component. Spat Spatiotemporal Epidemiol. 2017;22:27-37.

61. Grillet M-E, El Souki M, Laguna F, León JR. The periodicity of Plasmodium vivax and Plasmodium falciparum in Venezuela. Acta Trop. 2014;129:52-60.

62. Rodríguez DJ, Delgado L, Ramos S, Weinberger $V$, Rangel Y. A model for the dynamics of malaria in Paria Peninsula, Sucre State, Venezuela. Ecol Model. 2013;259:1-9.

63. Chuang T-W, Soble A, Ntshalintshali N, Mkhonta N, Seyama E, Mthethwa $\mathrm{S}$, et al. Assessment of climate-driven variations in malaria incidence in Swaziland: toward malaria elimination. Malar J. 2017;16:232.

64. Haque U, Hashizume M, Glass GE, Dewan AM, Overgaard HJ, Yamamoto T. The role of climate variability in the spread of malaria in Bangladeshi Highlands. PLoS ONE. 2010;5:e14341.

65. Chaves LF, Chuang T-W, Sasa M, Gutiérrez JM. Snakebites are associated with poverty, weather fluctuations, and El Niño. Sci Adv. 2015;1:e1500249.

66. Yamada K, Valderrama A, Gottdenker N, Cerezo L, Minakawa N, Saldaña A, et al. Macroecological patterns of American Cutaneous Leishmaniasis transmission across the health areas of Panamá (1980-2012). Parasite Epidemiol Control. 2016;1:42-55.

67. Chaves LF, Pascual M. Climate cycles and forecasts of cutaneous leishmaniasis, a nonstationary vector-borne disease. PLoS Med. 2006;3:e295.

68. Olmedo BA. El Niño en Panamá (Metereología E-Dd). Ciudad de Panamá: ETESA; 2006. p. 10

69. Olmedo B. Estado actual de las condiciones del Océano Pacífico Y su posible evolución durante el año 2015-2016. Panamá: ETESA-Gerencia de Climatología; 2016. p. 9.

70. Patz JA, Olson SH. Malaria risk and temperature: influences from global climate change and local land use practices. Proc Natl Acad Sci USA 2006;103:5635-6.

71. Stensgaard A-S, Vounatsou P, Onapa AW, Utzinger J, Pedersen EM, Kristensen TK, et al. Ecological drivers of Mansonella perstans infection in Uganda and patterns of co-endemicity with lymphatic filariasis and malaria. PLoS Negl Trop Dis. 2016;10:e0004319.

72. Rejmankova E, Roberts D, Harbach R, Pecor J, Peyton E, Manguin S, et al. Environmental and regional determinants of Anopheles (Diptera:
Culicidae) larval distribution in Belize, Central America. Environ Entomol. 1993;22:978-92.

73. Rejmankova E, Savage H, Rodriguez M, Roberts D, Rejmanek M. Aquatic vegetation as a basis for classification of Anopheles albimanus Weideman (Diptera: Culicidae) larval habitats. Environ Entomol. 1992;21:598-603.

74. Rejmankova E, Savage HM, Rejmanek M, Arredondo-Jimenez Jl, Roberts DR. Multivariate analysis of relationships between habitats, environmental factors and occurrence of Anopheline mosquito larvae Anopheles albimanus and A. pseudopunctipennis in Southern Chiapas, Mexico. J Appl Ecol. 1991;28:827-41.

75. Berti J, González J, Navarro-Bueno E, Zoppi E, Gordon E, Delgado L. Larval seasonality of the mosquito Anopheles aquasalis (Diptera: Culicidae) and other insects associated to its habitat in Sucre, Venezuela. Rev Biol Trop. 2010:58:777-87.

76. Berti J, Zimmerman R, Amarista J. Spatial and temporal distribution of anopheline larvae in two malarious areas in Sucre State, Venezuela. Mem Inst Oswaldo Cruz. 1993;88:353-62.

77. Chaves LF, Satake A, Hashizume M, Minakawa N. Indian Ocean dipole and rainfall drive a Moran effect in East Africa malaria transmission. J Infect Dis. 2012:205:1885-91.

78. Honjo K, Chaves LF, Satake A, Kaneko A, Minakawa N. When they don't bite, we smell money: understanding malaria bednet misuse. Parasitology. 2013;140:580-6.

79. Wallace R, Chaves LF, Bergmann L, CfJ Ayres Lopes, Hogerwerf L, et al. Clear-cutting disease control: capital-led deforestation, public health austerity, and vector-borne infection. New York: Springer; 2018.

80. Cáceres L, Rovira J, Torres R, García A, Calzada J, De La Cruz M. Caracterización de la transmisión de la malaria por Plasmodium vivax en la región fronteriza de Panamá con Costa Rica en el municipio de Barú, Panamá. Biomédica. 2012;32:557-69.

81. Chaves LF, Moji K. Density dependence, landscape and weather impacts on aquatic Aedes japonicus japonicus (Diptera: Culicidae) abundance along an urban altitudinal gradient. J Med Entomol. 2018. https://doi. org/10.1093/jme/tjx200

82. Chaves LF. Globally invasive, withdrawing at home: Aedes albopictus and Aedes japonicus facing the rise of Aedes flavopictus. Int J Biometeorol. 2016;60:1727-38.

83. Levins R. Toward an integrated epidemiology. Trends Ecol Evol. 1995;10:304.

84. Data Sources \& Accuracy for National Park Service Maps [https://www. nps.gov/hfc/carto/data-sources.cfm].

\section{Submit your next manuscript to BioMed Central and we will help you at every step:}

- We accept pre-submission inquiries

- Our selector tool helps you to find the most relevant journal

- We provide round the clock customer support

- Convenient online submission

- Thorough peer review

- Inclusion in PubMed and all major indexing services

- Maximum visibility for your research

Submit your manuscript at www.biomedcentral.com/submit
BioMed Central 